\title{
Obstetric pharmacokinetic dosing studies are urgently needed
}

\section{Shelley A. McCormack ${ }^{1}$ and Brookie M. Best ${ }^{1,2}{ }^{2}$}

' Pediatrics Department, School of Medicine, Rady Children's Hospital San Diego, University of California San Diego, San Diego, CA, USA

${ }^{2}$ Skaggs School of Pharmacy and Pharmaceutical Sciences, University of California San Diego, La Jolla, CA, USA

\section{Edited by:}

George Giacoia, National Institutes of Health, USA

\section{Reviewed by:}

Steve Caritis, University of Pittsburgh, USA

Zhaoxia Ren, National Institute of

Child Health and Human

Development, USA

${ }^{*}$ Correspondence:

Brookie M. Best, Skaggs School of Pharmacy and Pharmaceutical

Sciences, University of California San Diego, 9500 Gilman Drive, MC 0719,

La Jolla, CA 92093-0719, USA

e-mail:brookie@ucsd.edu
Use of pharmacotherapy during pregnancy is common and increasing. Physiologic changes during pregnancy may significantly alter the overall systemic drug exposure, necessitating dose changes. A search of PubMed for pharmacokinetic clinical trials showed 494 publications during pregnancy out of 35,921 total pharmacokinetic published studies (1.29\%), from the late 1960s through August 31, 2013. Closer examination of pharmacokinetic studies in pregnant women published since 2008 (81 studies) revealed that about a third of the trials were for treatment of acute labor and delivery issues, a third included studies of infectious disease treatment during pregnancy, and the remaining third were for varied ante-partum indications. Approximately, two-thirds of these recent studies were primarily funded by government agencies worldwide, one-quarter were supported by private nonprofit foundations or combinations of government and private funding, and slightly $<10 \%$ were supported by pharmaceutical industry. As highlighted in this review, vast gaps exist in pharmacology information and evidence for appropriate dosing of medications in pregnant women. This lack of knowledge and understanding of drug disposition throughout pregnancy place both the mother and the fetus at risk for avoidable therapeutic misadventures - suboptimal efficacy or excess toxicity - with medication use in pregnancy. Increased efforts to perform and support obstetric dosing and pharmacokinetic studies are greatly needed.

\section{Keywords: pharmacology, pharmacokinetics, pregnancy, obstetrics, maternal-fetal}

\section{INTRODUCTION}

Use of pharmacotherapy during pregnancy is common and increasing. From 1976 to 2008, the average number of medications (prescription and non-prescription) used during the first trimester increased from 1.6 to 2.6; this is an increase of approximately $60 \%$ (1). More recently, from 2006 to 2008 over $80 \%$ of women reported using at least one medication during the first trimester and over $90 \%$ reported using at least one medication at any point during the pregnancy (1). Given that during this time frame approximately 6.6 million pregnancies occurred per year in the United States (U.S.) (2), the issue of pharmacotherapy during pregnancy clearly has widespread relevance.

Increased use of medications during the first trimester is particularly concerning as this is a crucial period for organogenesis and, further, many women may be unaware of their pregnancy during this time. A recent review of 172 drugs approved by the Food and Drug Administration (FDA) from 2000 to 2010, conducted using the Teratogen Information System (TERIS), revealed insufficient data to determine teratogenic risk for nearly $98 \%$ of these drugs; over $70 \%$ actually had no pregnancy-related data available (3). Understanding teratogenic risk is important yet unfortunately understudied, especially for newer agents.

Despite the lack of safety data, often medication administration during pregnancy is unavoidable, with the benefits of treatment outweighing the possible risks. When medications need to be used during pregnancy, another concerning issue is the deficit of knowledge as to the proper dosing of pharmacotherapy during pregnancy. Understanding how to dose medications during pregnancy is crucial in order to ensure that the dose achieves therapeutic but not toxic plasma concentrations for both maternal and fetal wellbeing. Given the high and increasing rates of pharmacotherapy usage during pregnancy, gaps in pharmacology and appropriate dosing knowledge in pregnant women place both the mother and the fetus at risk for avoidable therapeutic misadventures.

The many physiologic changes throughout pregnancy affect pharmacokinetic parameters for pharmacotherapy administered during this time. The four primary processes of concern in pharmacokinetics, that is absorption, distribution, metabolism, and excretion, may all be influenced. Such pregnancy-related changes include changes in gastrointestinal motility and $\mathrm{pH}$ impacting absorption, expansion of total body water and plasma volume, and decreased concentrations of drug binding proteins affecting distribution, changes in drug metabolism rates by cytochrome P450 (CYP) and other metabolizing and transport enzymes, and increased glomerular filtration rate affecting urinary excretion (4). These various changes are not constant but rather fluctuate according to different patterns throughout the timeframe of pregnancy (4). These physiologic changes may have additive, synergistic, or competing effects on overall drug exposure. The clinical significance of these changes varies by drug, depending on the magnitude of the effect and the therapeutic window of the drug. The impact 
on overall drug exposure for any given drug is difficult to predict. To appropriately and safely dose drugs during pregnancy, these pharmacokinetic changes must be understood. Determination of the corresponding pharmacodynamic changes in pregnancy is also essential to understanding the pharmacokinetic changes in terms of implications for dosing. The objective of this focused review is to focus on the pharmacokinetic aspect to examine trends over time in the availability of maternal pharmacokinetic and dosing data for medications during pregnancy, to describe the drug classes or disease states, which have been studied for dosing determination to some degree during pregnancy, and to characterize sources of support for pharmacokinetic studies in pregnant women.

\section{METHODS}

A literature search was conducted within PubMed to assess the number of pharmacokinetic trials in pregnancy conducted over time and to determine which classes of drugs have been studied. A search of PubMed was performed for the terms "pharmacokinetics" and "pregnancy" with filters for "human" (species) and publication date through August 31, 2013 with no start date specified. "Pharmacokinetics" and "pregnancy" were not entered as $\mathrm{MeSH}$ terms after finding that many articles directly addressing pharmacokinetics were not indexed to have this as a MeSH term but rather had something more specific listed as a MeSH term instead, such as "adenine/pharmacokinetics." A publication type filter was used for "clinical trial" and, separately, to search for all types except "case report" and "review."

The results from this search strategy were stratified by year. Articles with electronic publication (e-publication) ahead of print were categorized in the year of print publication and not epublication to avoid double-counting. All of the results categorized as clinical trials beginning with January 1, 2008 were more closely examined as follows. Those articles unrelated to the actual time period of pregnancy, despite being important to the larger field of women's health, were excluded for the purposes of this review. Examples of such excluded topics include in vitro fertilization (IVF) treatments, breastfeeding and other postpartum issues, and sexually transmitted diseases outside of pregnancy. Articles pertaining to pregnancy but unrelated to pharmacotherapy, including environmental exposures, were also excluded. Finally, articles completely unrelated to pregnancy or humans and in vitro studies that appeared in the search results were excluded.

Additionally, a list of publications affiliated with the ObstetricFetal Pharmacology Research Unit (OPRU) network, provided on their website, was reviewed for additional publications and to test the completeness of the PubMed search strategy. Publications from 2008 through August 31, 2013 were manually reviewed for inclusion based on the same criteria as described above for the PubMed search results.

The non-excluded results from both the clinical trial PubMed and OPRU list searches were classified into broad categories as follows: (1) medication administration and parameter measurements occurring exclusively during labor and delivery and typically involving pain control or infectious disease (ID) prophylaxis [antiretrovirals (ARVs), antibiotics], (2) medications for treatment or prevention of pre-eclampsia or hemolysis, elevated liver enzymes, low platelets (HELLP) syndrome, and tocolytic therapy,
(3) ARV regimens during pregnancy excluding one-time doses administered during labor, (4) non-HIV ID pharmacotherapy during pregnancy but again excluding doses given solely around the time of labor for prophylactic purposes, (5) vitamins and minerals during pregnancy (except magnesium for pre-eclampsia), and (6) studies of medications during pregnancy that do not fit into the other categories. Of the described six categories, categories 1-2 include studies focusing on acute and subacute conditions surrounding the time of delivery. Categories 3-6 focus on conditions requiring treatment at any time throughout pregnancy. Most studies involving a single dose at time of labor and delivery were placed in categories 1-2. However, a few such studies were placed into the categories 3-6 if they involved drug administration immediately prior to delivery but in a patient with scheduled cesarean and no onset of labor. This decision was made because the goal of such studies was in part to determine third-trimester (pre-labor) pharmacokinetic parameters. Since the dose was administered so close to delivery in such cases, fetal exposure could simultaneously be ascertained.

For the studies published after January 1, 2008, primary sources of funding were determined where possible. Acknowledgments and listings of funding support in the full texts of the articles were examined to categorize primary funding sources.

Finally, out of concern that the PubMed "clinical trial" filter may exclude some otherwise relevant articles, a filter for all publication types except "review" and "case report" was placed and a thorough manual review was performed for 2012 and 2013 (through August 31). This was performed to ascertain the rough proportion of total articles captured utilizing the "clinical trial" filter and allow for potential extrapolation.

\section{RESULTS}

The overall search of PubMed as described and using the "clinical trial" filter yielded 464 results. Without the term "pregnancy" this same search had 35,921 results, indicating that only $1.29 \%$ $(464 / 35,921)$ of the pharmacokinetic studies found in the search involved pregnant women. As can be visualized in Figures $\mathbf{1}$ and 2, absolute number of pharmacokinetic studies, both with and without pregnancy data, have steadily increased over the past four decades with particularly large increases from the mid-1980s to mid-1990s. However, as shown in Figure 3 the proportion of these studies involving pregnancy has been relatively constant since around 1990; years prior to the mid-1980s had significant fluctuations in this proportion as expected given the low absolute values. The year 2013 is displayed in Figure 1 for informational purposes; note that it only includes those articles indexed in MEDLINE by August 31, 2013. The number of articles for 2013 were not adjusted to account for the partial year as scaling for 8 of 12 months did not seem reasonable given the inconsistent multimonth delay between publication and appearance in PubMed. When searching for all except "review" and "case report" publication types, the total number of articles was 156,539 with 3633 of these in pregnancy $(2.3 \%)$. However, as per the manual review of a subset of this broader search described below, most of the articles when searching by "clinical trial" were relevant whereas most found by the broader search were excluded. Hence, the percentage of 1.29 from the narrower search is likely more reliable and 


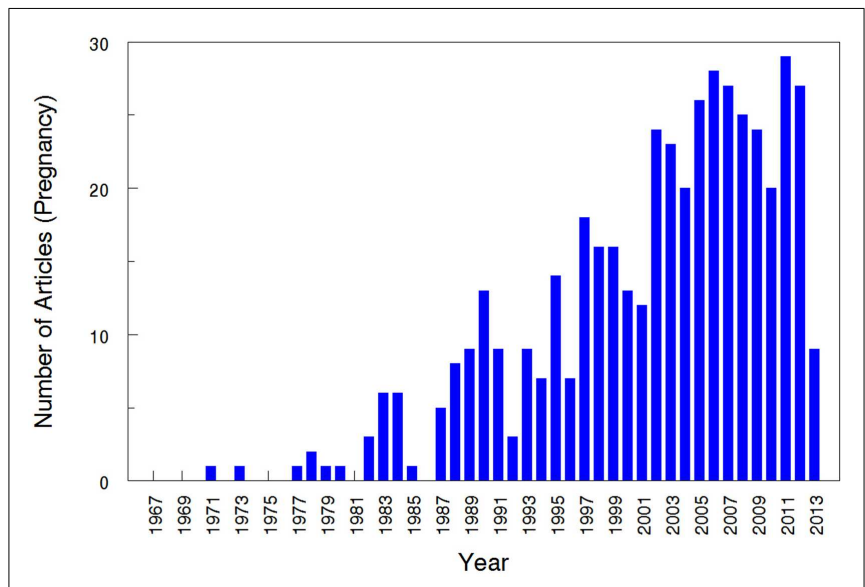

FIGURE 1 | Number of pharmacokinetic clinical trials conducted in pregnancy. The year 2013 includes those articles index for MEDLINE by August 31, 2013 only. This figure displays the absolute number of articles meeting the search terms, displayed by year.

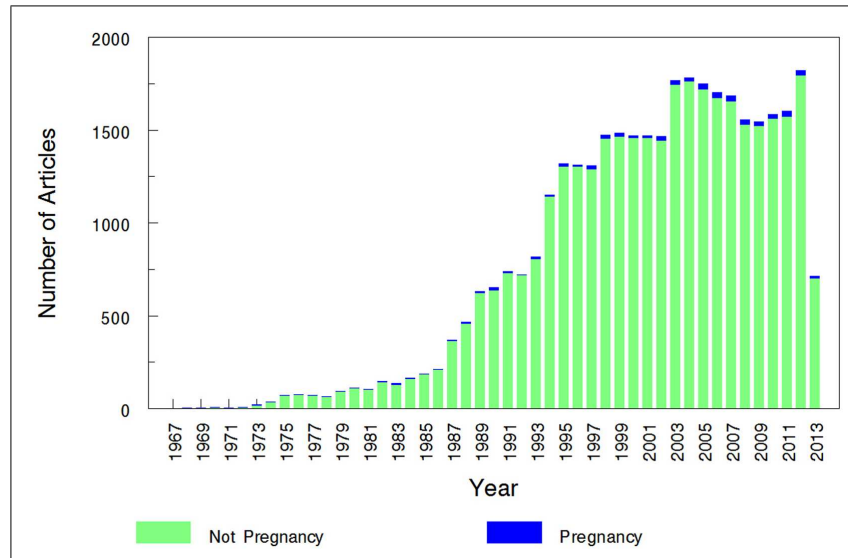

FIGURE 2 | Number of pregnancy and non-pregnancy pharmacokinetic clinical trials. The year 2013 includes those articles index for MEDLINE by August 31, 2013 only. This figure displays the number of pregnancy pharmacokinetic articles along with all pharmacokinetic articles (pregnancy search term excluded) found to otherwise match the search terms specified.

the findings from the broader search were not further stratified by year. Additional pregnancy studies identified through the OPRU listing search are not included in these overall percentages as there was not a comparable method available to check for additional studies in PubMed associated with the overall (pregnancy plus non-pregnancy) count.

When narrowing the above search, limited to "clinical trial," to the time frame of January 1, 2008 to August 31, 2013, 134 articles remained. Of these, 59 were excluded based on the criteria specified in the Section "Methods" above, leaving 75 for further classification. Of the 75 remaining studies, 8 were drug studies that did not measure drug concentrations and appeared unrelated to pharmacokinetics despite this being one of the search terms. These studies typically involved measurement of an outcome (e.g., change in

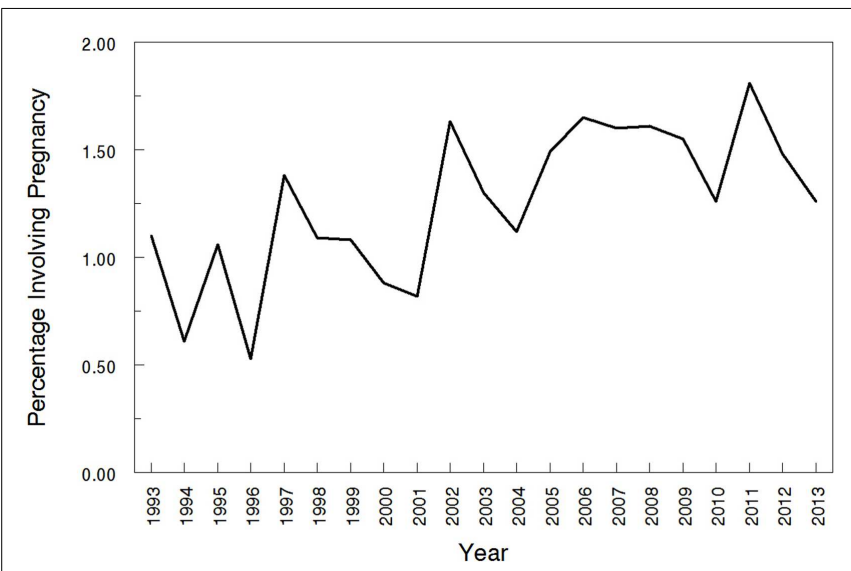

FIGURE 3 | Proportions of pharmacokinetic clinical trials conducted in pregnancy. The year 2013 includes those articles index for MEDLINE by August 31, 2013 only. This figure shows the percentage of pregnancy pharmacokinetic articles compared to all pharmacokinetic articles published since the early 1990 s.

blood pressure) in response to drug dosing adjustments without measuring the drug concentration itself. Given that these studies did not meet the exclusion criteria and still contribute to improved pharmacotherapy in pregnancy, they were included in this review but noted accordingly in Table 1 .

Six additional relevant studies, approximately one per year, were identified by review of the OPRU studies listing. These were not found by PubMed only because they were not indexed as "clinical trial" (publication type), but upon careful review "clinical trial" indexing would have been appropriate. This resulted in a total of 81 studies included from the two search methods.

Approximately one-third of studies (26/81) classified were focused on pharmacokinetic issues during or immediately preceding labor; specifically, 19 studies were during labor and delivery and 7 more focused on pre-eclampsia and HELLP management prior to delivery or tocolytics to delay delivery. In comparison, 55 studies addressed medications given chronically during pregnancy. Of the chronic medications, 16 of the 55 studies were for HIV treatment and vertical transmission prevention. More detailed results of this classification are displayed in Table 1 and Figure 4.

Within the non-HIV ID category, the sub-classification by year is as follows. No articles have been published yet in 2013 . In 2012 azithromycin was studied (47). 2011 included one study of metronidazole for bacterial vaginosis (48), one study of oseltamivir (49), and two studies of anti-malarial regimens (50, 51). In 2010 and 2009 two studies of anti-malarial regimens in pregnancy were published each year (52-55). 2008 had one study of an anti-malarial regimen (56) and one of amoxicillin in preterm premature rupture of membranes (57).

The final category, containing all drug classes given throughout pregnancy but not related to IDs, contained a sub-classification of available studies by year as follows. In the first 8 months of 2013, the only medication studied was doxylamine/pyridoxine for nausea/vomiting in pregnancy (61). In 2012, these medications included metformin for Type 2 diabetes in obese pregnant 
Table 1 | Classification of search results for recent clinical trials of pharmacokinetics and pregnancy.

\begin{tabular}{|c|c|c|c|c|c|c|c|}
\hline \multirow[t]{2}{*}{ Year } & \multirow{2}{*}{$\begin{array}{l}\text { Total (PubMed }+ \\
\text { OPRU) }\end{array}$} & \multicolumn{2}{|c|}{ Acute/subacute } & \multicolumn{4}{|c|}{ Chronic } \\
\hline & & $\begin{array}{l}\text { Intra- } \\
\text { partum }\end{array}$ & $\begin{array}{l}\text { Late ante- } \\
\text { partum }\end{array}$ & $\begin{array}{l}\text { ARVs ante- } \\
\text { partum }\end{array}$ & $\begin{array}{l}\text { Other ID } \\
\text { ante-partum }\end{array}$ & $\begin{array}{l}\text { Vitamins/minerals } \\
\text { ante-partum }\end{array}$ & $\begin{array}{l}\text { Other medications } \\
\text { ante-partum }\end{array}$ \\
\hline 2013 (1/1-8/31 only) & 9 & 3 & 2 & 2 & 0 & 1 & 1 \\
\hline 2012 & 14 & 2 & $2^{\mathrm{a}}$ & 4 & 1 & $1^{\mathrm{a}}$ & 4 \\
\hline 2010 & 11 & $4^{b}$ & 1 & 1 & 2 & 0 & 3 \\
\hline 2009 & 16 & 3 & 1 & 2 & 2 & 1 & $7^{b}$ \\
\hline 2008 & 14 & $3^{\mathrm{a}}$ & 1 & 3 & 2 & 0 & $5^{\mathrm{a}}$ \\
\hline Total (1/2008-8/2013) & 81 & 19 & 7 & 16 & 11 & 3 & 25 \\
\hline
\end{tabular}

Data for 2013 only includes those articles indexed for MEDLINE as "clinical trial" (publication type) by August 31, 2013. The "intra-partum" category includes medications given at the time of delivery, typically for pain control or infectious disease prophylaxis. The "late ante-partum" category includes pharmacotherapy given for pre-eclampsia; management of syndrome of hemolysis, elevated liver enzymes, and low platelets (HELLP); or to induce tocolysis. The remaining categories include medications administered earlier in pregnancy (i.e., prior to labor/delivery) only.

ARVs, antiretrovirals; ID, infectious disease. References for each column: intra-partum (5-23), late ante-partum (24-30), ARVs (31-46), other ID (47-57), vitamins/minerals (58-60), other medications (61-85).

${ }^{a}$ One study in this category did not measure drug concentrations.

${ }^{b}$ Two studies in this category did not measure drug concentrations.

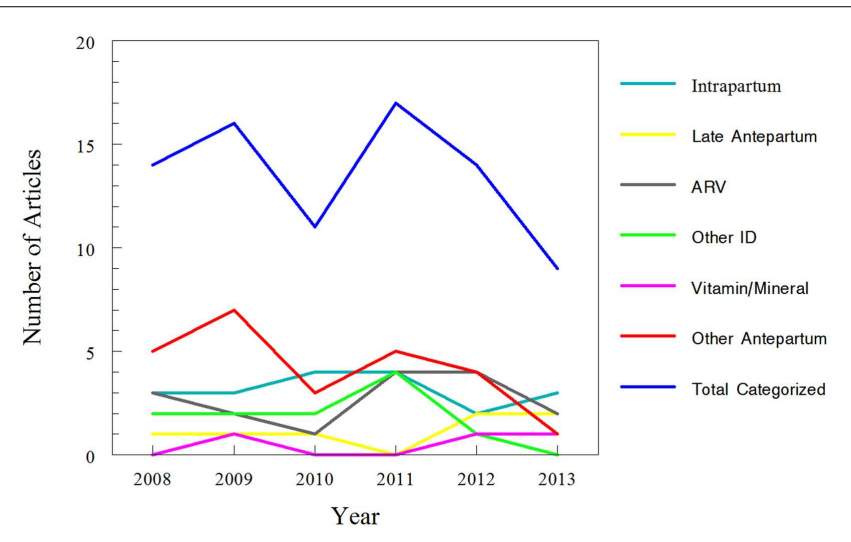

FIGURE 4 |Trends for classification of search results for recent clinical trials of pharmacokinetics and pregnancy. Data for 2013 only includes those articles indexed for MEDLINE by August 31, 2013. The "intra-partum" category includes medications given at the time of delivery, typically for pain control or infectious disease prophylaxis. The "late ante-partum" category includes pharmacotherapy given for pre-eclampsia; management of syndrome of hemolysis, elevated liver enzymes, and low platelets (HELLP); or to induce tocolysis. The remaining categories include medications administered earlier in pregnancy (i.e., prior to labor/delivery) only.

women (62), tacrolimus (63), 17-hydroxyprogesterone for prevention of preterm labor in patients at risk (64), and doxorubicin and ifosfamide for high-grade sarcomas during pregnancy (65). In 2011, the medications were buprenorphine for opioid dependence treatment (66), two studies of methadone written by the same authors $(67,68)$, intravenous immunoglobulin (IVIG) (69), and labetalol (70). 2010 had one study of fluoxetine (71), one of metformin (72), and one of glucose kinetics (73). In 2009, studies addressed dydrogesterone to prevent miscarriage in patients with second trimester vaginal bleeding (74), doxylamine/pyridoxine for nausea/vomiting of pregnancy (75), sumatriptan/naratriptan (76), safety of serotonin reuptake inhibitors (SSRIs)/serotonin norepinephrine reuptake inhibitors (SNRIs) (77), glyburide for gestational diabetes (78), lamotrigine for epilepsy (79), and clonidine (80). The drugs studied in 2008 were sertraline (81), enoxaparin (82), glyburide (83), aspirin in patients whose pregnancy was achieved via IVF (84), and finally midazolam and digoxin (as probe substrates studying CYP3A enzymes and P-glycoprotein) (85).

When broadening the search criteria to include all publication types except for case reports and reviews, 634 additional articles were found from January 1, 2008 through August 31, 2013. Narrowing from January 1, 2012 to August 31, 2013 resulted in 180 additional articles. When manually reviewing each of these 180 results for original data relevant to dosing during pregnancy, only 18 were relevant (14 in 2012 and 4 through August 2013). Combining with the 23 relevant articles found by searching for "clinical trial" yields a total of 41 relevant articles during the time period and indicates that the broader count for the other years reported in Table 1 may be increased by approximately $44 \%$. The additional relevant studies included three studies related to intra-partum pain management (86-88), four on ARVs ante-partum (89-92), six on antimalarials (93-98) of which many are by the same authors, one on vitamin D (99), and five on other ante-partum pharmacotherapy. Of these latter four studies, one study addressed anti-D IgG dosing (100), one addressed anti-tumor necrosis factor for inflammatory bowel disease (101), and two modeled activities of CYP enzymes (102, 103).

Primary funding sources for the clinical trials published since January 1, 2008 were determined if available. Of the 81 articles included, all except for 13 articles stated their source of funding. See Figure $\mathbf{5}$ for the approximate distribution of funding sources. 


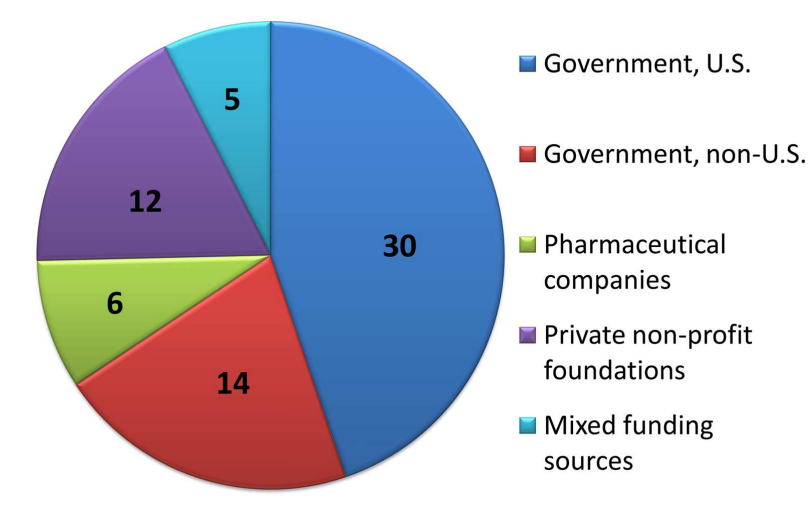

FIGURE 5 | Distribution of primary funding sources. For clinical trials with funding source information provided, the number of studies primarily funded by each source is displayed.

Of the 68 clinical trials with explicit funding information, 30/68 (44\%) were funded via U.S. government organizations; one article was funded by U.S. Department of Agriculture (USDA) and 29 were by various institutes of the National Institutes of Health (NIH). The primary NIH institutes involved were the National Institute of Allergy and Infectious Diseases (NIAID) and the Eunice Kennedy Shriver National Institute of Child Health and Human Development (NICHD); other supporting institutes included the National Institute of Diabetes and Digestive and Kidney Diseases (NIDDK), the National Institute of Mental Health (NIMH), the National Institute on Drug Abuse (NIDA), and the National Center for Research Resources (NCRR). The OPRU network, funded by the NICHD was, as per their listing of affiliated publications, associated with 11 of the studies $(26,27,48,49,61,63,64,72,78,80$, 83). Some of these were explicitly sponsored by OPRU as per the author listing or funding acknowledgment; others stated a nongovernmental source of funding but presumably were included in this listing based on author affiliation.

Another 14/68 (21\%) of the studies were funded by governmental funding from outside the U.S., including Brazil (five studies), Australia (two studies), Belgium, Canada, Germany, Hong Kong, Japan, Netherlands, and Switzerland. An additional study was a joint effort of government funding from the U.S. (NIH), France, and Thailand.

Drug companies directly funded 6/68 (8.8\%) of studies, excluding legally independent foundations that receive support from drug companies. Private non-profit foundations (U.S. and abroad) funded $12 / 68$ (18\%) of the studies, and combinations of public and private funding were responsible for the remaining 5/68 (7\%) studies.

\section{DISCUSSION}

This review found that only $1.29 \%$ of pharmacokinetic clinical trials indexed in PubMed provide data for pregnant women. A search for pregnancy rates within the National Vital Statistics Reports, at present containing data through 2008 , revealed a yearly pregnancy rate for females in the U.S., ranging from 10.4 to $10.7 \%$ (2). This would roughly correspond to a population of yearly pregnancy rate ranging from 5.2 to $5.4 \%$. These rates are up to five times higher than the rates of pregnancy-related studies available during this same time frame, which were $1.1-1.6 \%$ as per this review. The decision to use medications during pregnancy should be based on a complete understanding of the risks and benefits and should include an understanding of how to optimally dose these medications in this population. Unfortunately, the knowledge of the risks, benefits, and optimal dosing are often incomplete; during pregnancy, these knowledge gaps in many cases are vast.

This review found that relative to other drug classes, the ARVs have a larger number (16/81:20\% since 2008) of pharmacokinetic clinical trials during pregnancy. This is perhaps in part due to explicit devotion of resources and the medical community's agreement and public acceptability that these medications are not only for maternal wellbeing but to prevent transmission of HIV to the fetus. These HIV studies have found that doses for some medications but not others do need to be altered during pregnancy. The findings of the pharmacology studies in pregnant women with HIV highlight the need for studies of the multitudes of other medications and drug classes being used by pregnant women.

Over time many women are postponing childbearing to an older age (2), increasing the risk of concomitant chronic health issues throughout pregnancy. Further, advances in reproductive technology can potentially enable women to become pregnant who would not have been healthy enough otherwise. Certain chronic conditions such as Type 2 diabetes are frequently appearing at younger ages than they have in the past and may exist prior to pregnancy (104-106). All of these issues increase the risk that a pregnant female will have a chronic medical condition prior to pregnancy that necessitates chronic pharmacotherapy during pregnancy. Such pharmacotherapy requires knowledge of the proper dosing in order to achieve the proper drug concentrations for efficacious management of the condition and to prevent poor fetal outcomes associated with poor maternal disease control.

This raises the question of which medical conditions are seen most frequently in the childbearing population and if sufficient evidence exists to treat these conditions appropriately during pregnancy. A recent study surveyed mothers to determine which medications they had used during the first trimester of pregnancy (107). The majority of oral medications in the list generated by that study fell into the categories of antibiotics, analgesics, anti-emetics, diabetes treatment (metformin and insulin), and psychiatric medications (primarily antidepressants) (107). Of these, data were significantly lacking for the psychiatric medications as well as for some of the antibiotics. Proper treatment of both infections and psychiatric illnesses is crucial in pregnancy for both maternal and fetal wellbeing - perhaps even more crucial than in non-pregnant populations.

For the specific psychiatric example of depression, prevalence of depression from 2007 to 2010 in females ages 18-39 was approximately $10 \%$ (108); this encompasses most of the childbearing years. In the next age category, ages $40-59$, this rate was similar at $12 \%$ (108). However, for ages $\geq 60$, the depression rate in females drops to $7 \%$ (108). Based on these prevalence rates, the common usage of antidepressants during pregnancy is not surprising. However, over the time period closely examined in this review (January 2008 to August 2013), only three pharmacokinetic studies 
were published pertaining to psychiatric medications. These studies only addressed selective SSRIs and one SNRI. Further, while all three studies measured maternal SSRI or SNRI concentrations, only two $(71,81)$ were designed to determine maternal pharmacokinetic parameters and proper dosing. The third focused on correlating the maternal drug concentrations to cord concentrations and neonatal behavioral outcomes (77). Increased inclusion of the pregnant population in pharmacokinetic studies of antidepressants is a necessary change in order to address this knowledge gap.

In addition to the need for increased awareness of the scope of this problem of insufficient pharmacokinetic trials during pregnancy, increased incentive for government and non-government funding of these trials is also needed. Currently, the pharmaceutical industry has no incentive or mandate to fund trials that include pregnant patients as part of the drug approval process, and, as revealed, the drug companies were the primary sponsors of only $8.8 \%$ of the trials discussed. One possible solution to this issue would be to pass legislation providing the FDA with the authority to mandate pharmaceutical companies to complete testing of any medications that would likely be used by the pregnant population. An additional approach would be increasing the support of pharmacokinetic trials in pregnancy by private and by government-funded organizations. Government support for existing disease-specific or pharmacology-related clinical research networks charged to perform obstetric-fetal pharmacology studies could be increased to allow for more sites, more basic/translational studies, and more clinical trials. Another approach could be that each NIH institute (NIDDK, NHLBI, NIAID, NICHD, NIMH, etc.) maintain a certain percentage of pregnancy dosing-related studies within its portfolio of supported studies.

In moving forward to incentivize, mandate, or simply encourage and support an increased number of pharmacokinetic studies during pregnancy, the field of pediatrics provides one potential model. Until recent years, similarly, dosing information was lacking for most medications frequently administered to pediatric patients. This problem is now slowly improving through a series of government-based incentives and mandates (109-111). Both the pediatric and pregnant populations face a reluctance to perform clinical trials, in part due to legitimate ethical concerns. However, as pharmacotherapy must often be given in either group, the result of not testing in these groups appears to be gradually gaining recognition as an equally legitimate ethical concern. Hopefully, the field of obstetrical pharmacology will be able to make similar or more progress as the pediatric pharmacology field in the near future.

This brief, focused review did not capture all pharmacokinetic studies during the time frame listed, as evidenced by the $44 \%$ increase in studies when the formal "clinical trial" filter was removed. However, this was not designed as a comprehensive meta-analysis. Rather, the goal was to provide a general overview of trends over time and for various classes of drugs in order to raise awareness of gaps in the literature and focus future efforts accordingly. The inevitable shortcomings of the search strategy do not change the overall findings relative to this goal. This review found that the number of pharmacokinetic studies performed in pregnant women are exceedingly low, despite the fact that medication use during pregnancy is widespread and increasing.
This review does not focus on pharmacodynamic studies. A brief search using this term yields 828 studies in pregnancy since 2012 even with the restrictive "clinical trial" filter, but many of the automated findings are surprisingly irrelevant to pharmacotherapy and very few are related to dose determination. Many of the dosing studies are for treatment given only at the time of delivery, such as pain control, for which outcome can be promptly assessed. It is likely that there is a shortage of pharmacodynamic studies in pregnancy, but further investigation is needed to ascertain the scope of this problem. This issue is crucial, as without accompanying pharmacodynamic data the pharmacokinetic studies' usefulness is limited.

An understanding of the clinical pharmacology of medications during pregnancy is critical to develop optimal dosing regimens. Inappropriate dosing of medications during pregnancy can have minor to profound adverse consequences for both the mother and the fetus. Increased number of studies and sources of support for pharmacokinetic studies in pregnant women are greatly needed.

\section{ACKNOWLEDGMENTS}

This publication was supported by grant number 1TL1RR03197 from the NIH National Center for Research Resources (Shelley A. McCormack). The authors have no conflicts of interest to declare. Shelley A. McCormack drafted the manuscript. Shelley A. McCormack and Brookie M. Best designed the content, critically revised, approved the final version, and agreed to be accountable for all aspects of the work.

\section{REFERENCES}

1. Mitchell AA, Gilboa SM, Werler MM, Kelley KE, Louik C, Hernandez-Diaz $\mathrm{S}$, et al. Medication use during pregnancy, with particular focus on prescription drugs: 1976-2008. Am J Obstet Gynecol (2011) 205(1): 51.e1-8. doi:10.1016/j.ajog.2011.02.029

2. Ventura SJ, Curtin SC, Abma JC, Henshaw SK. Estimated pregnancy rates and rates of pregnancy outcomes for the United States, 1990-2008. Natl Vital Stat Rep (2012) 60(7):1-21.

3. Adam MP, Polifka JE, Friedman JM. Evolving knowledge of the teratogenicity of medications in human pregnancy. Am J Med Genet C Semin Med Genet (2011) 157C(3):175-82. doi:10.1002/ajmg.c.30313

4. Best BM, Capparelli EV. Implications of gender and pregnancy for antiretroviral drug dosing. Curr Opin HIV AIDS (2008) 3(3):277-82. doi:10.1097/COH. 0b013e3282f39f7e

5. Vardhanabhuti S, Acosta EP, Ribaudo HJ, Severe P, Lalloo U, Kumarasamy N, et al. Clinical and genetic determinants of plasma nevirapine exposure following an intrapartum dose to prevent mother-to-child HIV transmission. J Infect Dis (2013) 208(4):662-71. doi:10.1093/infdis/jit223

6. Frank M, Harms G, Kunz A, Kloft C. Population pharmacokinetic analysis of a nevirapine-based HIV-1 prevention of mother-to-child transmission program in Uganda to assess the impact of different dosing regimens for newborns. J Clin Pharmacol (2013) 53(3):294-304. doi:10.1177/0091270012448397

7. Kulo A, Peeters MY, Allegaert K, Smits A, de Hoon J, Verbesselt R, et al. Pharmacokinetics of paracetamol and its metabolites in women at delivery and post-partum. Br J Clin Pharmacol (2013) 75(3):850-60. doi:10.1111/j.13652125.2012.04402.x

8. Kokki M, Franco MG, Raatikainen K, Valitalo P, Sankilampi U, Heinonen S, et al. Intravenous oxycodone for pain relief in the first stage of labour - maternal pharmacokinetics and neonatal exposure. Basic Clin Pharmacol Toxicol (2012) 111(3):182-8. doi:10.1111/j.1742-7843.2012.00884.x

9. Muro EP, Fillekes Q, Kisanga ER, L'Homme R, Aitken SC, Mariki G, et al. Intrapartum single-dose carbamazepine reduces nevirapine levels faster and may decrease resistance after a single dose of nevirapine for perinatal HIV prevention. J Acquir Immune Defic Syndr (2012) 59(3):266-73. doi:10.1097/QAI. 0b013e31824234d8 
10. Flynn PM, Mirochnick M, Shapiro DE, Bardeguez A, Rodman J, Robbins B, et al. Pharmacokinetics and safety of single-dose tenofovir disoproxil fumarate and emtricitabine in HIV-1-infected pregnant women and their infants. Antimicrob Agents Chemother (2011) 55(12):5914-22. doi:10.1128/AAC.00544-11

11. Pevzner L, Swank M, Krepel C, Wing DA, Chan K, Edmiston CE Jr. Effects of maternal obesity on tissue concentrations of prophylactic cefazolin during cesarean delivery. Obstet Gynecol (2011) 117(4):877-82. doi:10.1097/AOG. 0b013e31820b95e4

12. de Barros Duarte L, Dantas Moises EC, Cavalli RC, Lanchote VL, Duarte G, da Cunha SP. Distribution of bupivacaine enantiomers and lidocaine and its metabolite in the placental intervillous space and in the different maternal and fetal compartments in term pregnant women. J Clin Pharmacol (2011) 51(2):212-7. doi:10.1177/0091270010365551

13. Bhattarai B, Bhat SY, Upadya M. Comparison of bolus phenylephrine, ephedrine and mephentermine for maintenance of arterial pressure during spinal anesthesia in cesarean section. JNMA J Nepal Med Assoc (2010) 49(177):23-8.

14. Guasch E, Gilsanz F, Diez J, Alsina E. Maternal hypotension with low doses of spinal bupivacaine or levobupivacaine and epidural volume expansion with saline for cesarean section. Rev Esp Anestesiol Reanim (2010) 57(5):267-74. doi:10.1016/S0034-9356(10)70226-7

15. Muller AE, Mouton JW, Oostvogel PM, Dorr PJ, Voskuyl RA, DeJongh J, et al. Pharmacokinetics of clindamycin in pregnant women in the peripartum period. Antimicrob Agents Chemother (2010) 54(5):2175-81. doi:10.1128/ AAC.01017-09

16. Kaandorp JJ, Benders MJ, Rademaker CM, Torrance HL, Oudijk MA, de Haan TR, et al. Antenatal allopurinol for reduction of birth asphyxia induced brain damage (ALLO-Trial); a randomized double blind placebo controlled multicenter study. BMC Pregnancy Childbirth (2010) 10:8. doi:10.1186/14712393-10-8

17. Chantarangsu S, Cressey TR, Mahasirimongkol S, Capparelli E, Tawon Y, NgoGiang-Huong N, et al. Influence of CYP2B6 polymorphisms on the persistence of plasma nevirapine concentrations following a single intra-partum dose for the prevention of mother to child transmission in HIV-infected Thai women. J Antimicrob Chemother (2009) 64(6):1265-73. doi:10.1093/jac/ dkp351

18. Ngan Kee WD, Khaw KS, Tan PE, Ng FF, Karmakar MK. Placental transfer and fetal metabolic effects of phenylephrine and ephedrine during spinal anesthesia for cesarean delivery. Anesthesiology (2009) 111(3):506-12. doi:10.1097/ALN. 0b013e3181b160a3

19. Hirt D, Urien S, Ekouevi DK, Rey E, Arrive E, Blanche S, et al. Population pharmacokinetics of tenofovir in HIV-1-infected pregnant women and their neonates (ANRS 12109). Clin Pharmacol Ther (2009) 85(2):182-9. doi:10.1038/clpt.2008.201

20. Moises EC, Duarte Lde B, Cavalli Rde C, Marques MP, Lanchote VL, Duarte G, et al. Pharmacokinetics of lidocaine and its metabolite in peridural anesthesia administered to pregnant women with gestational diabetes mellitus. Eur J Clin Pharmacol (2008) 64(12):1189-96. doi:10.1007/s00228-008-0544-0

21. Bamigboye AA, Justus HG. Ropivacaine abdominal wound infiltration and peritoneal spraying at cesarean delivery for preemptive analgesia. Int J Gynaecol Obstet (2008) 102(2):160-4. doi:10.1016/j.ijgo.2008.03.019

22. Thomas A, Ukpoma OK, Inman JA, Kaul AK, Beeson JH, Roberts KP. Quantification of penicillin $\mathrm{G}$ during labor and delivery by capillary electrophoresis. J Biochem Biophys Methods (2008) 70(6):992-8. doi:10.1016/j. jbbm.2007.05.002

23. Benaboud S, Ekouevi DK, Urien S, Rey E, Arrive E, Blanche S, et al. Population pharmacokinetics of nevirapine in HIV-1-infected pregnant women and their neonates. Antimicrob Agents Chemother (2011) 55(1):331-7. doi:10.1128/AAC. 00631- 10

24. Salinger DH, Mundle S, Regi A, Bracken H, Winikoff B, Vicini P, et al. Magnesium sulphate for prevention of eclampsia: are intramuscular and intravenous regimens equivalent? A population pharmacokinetic study. BJOG (2013) 120(7):894-900. doi:10.1111/1471-0528.12222

25. Giorgi VS, Peracoli MT, Peracoli JC, Witkin SS, Bannwart-Castro CF. Silibinin modulates the NF-kappab pathway and pro-inflammatory cytokine production by mononuclear cells from preeclamptic women. JReprod Immunol (2012) 95(1-2):67-72. doi:10.1016/j.jri.2012.06.004

26. Haas DM, Quinney SK, Clay JM, Renbarger JL, Hebert MF, Clark S, et al. Nifedipine pharmacokinetics are influenced by CYP3A5 genotype when used as a preterm labor tocolytic. Am J Perinatol (2013) 30(4):275-81. doi:10.1055/ s-0032-1323590

27. Haas DM, Quinney SK, McCormick CL, Jones DR, Renbarger JL. A pilot study of the impact of genotype on nifedipine pharmacokinetics when used as a tocolytic. J Matern Fetal Neonatal Med (2012) 25(4):419-23. doi:10.3109/ 14767058.2011.583700

28. Abbade JF, Costa RA, Martins AM, Borges VT, Rudge MV, Peracoli JC. Zuspan's scheme versus an alternative magnesium sulfate scheme: randomized clinical trial of magnesium serum concentrations. Hypertens Pregnancy (2010) 29(1):82-92. doi:10.3109/10641950902928704

29. Konda A, Ito T, Yoshida H, Toda T, Hayakawa T, Inotsume N. Pharmacokinetics of ritodrine diastereomers in patients pregnant with singletons and twins. Eur J Clin Pharmacol (2009) 65(9):913-7. doi:10.1007/s00228-009-0665-0

30. Juon AM, Kuhn-Velten WN, Burkhardt T, Krahenmann F, Zimmermann R, von Mandach U. Nifedipine gastrointestinal therapeutic system (GITS) as an alternative to slow-release for tocolysis - tolerance and pharmacokinetic profile. Eur J Obstet Gynecol Reprod Biol (2008) 140(1):27-32. doi:10.1016/j.ejogrb.2008. 02.003

31. Kreitchmann R, Best BM, Wang J, Stek A, Caparelli E, Watts DH, et al. Pharmacokinetics of an increased atazanavir dose with and without tenofovir during the third trimester of pregnancy. J Acquir Immune Defic Syndr (2013) 63(1):59-66. doi:10.1097/QAI.0b013e318289b4d2

32. Fayet-Mello A, Buclin T, Guignard N, Cruchon S, Cavassini M, Grawe C, et al. Free and total plasma levels of lopinavir during pregnancy, at delivery and postpartum: implications for dosage adjustments in pregnant women. Antivir Ther (2013) 18(2):171-82. doi:10.3851/IMP2328

33. Fang A, Valluri SR, O'Sullivan MJ, Maupin R, Jones T, Delke I, et al. Safety and pharmacokinetics of nelfinavir during the second and third trimesters of pregnancy and postpartum. HIV Clin Trials (2012) 13(1):46-59. doi:10.1310/ hct 1301-046

34. Stek AM, Best BM, Luo W, Capparelli E, Burchett S, Hu C, et al. Effect of pregnancy on emtricitabine pharmacokinetics. HIV Med (2012) 13(4):226-35. doi:10.1111/j.1468-1293.2011.00965.x

35. Else LJ, Douglas M, Dickinson L, Back DJ, Khoo SH, Taylor GP. Improved oral bioavailability of lopinavir in melt-extruded tablet formulation reduces impact of third trimester on lopinavir plasma concentrations. Antimicrob Agents Chemother (2012) 56(2):816-24. doi:10.1128/AAC.05186-11

36. Cressey TR, Stek A, Capparelli E, Bowonwatanuwong C, Prommas S, Sirivatanapa $\mathrm{P}$, et al. Efavirenz pharmacokinetics during the third trimester of pregnancy and postpartum. J Acquir Immune Defic Syndr (2012) 59(3):245-52. doi:10.1097/QAI.0b013e31823ff052

37. Beigi R, Noguchi L, Parsons T, Macio I, Kunjara Na Ayudhya RP, Chen J, et al. Pharmacokinetics and placental transfer of single-dose tenofovir $1 \%$ vaginal gel in term pregnancy. J Infect Dis (2011) 204(10):1527-31. doi:10.1093/infdis/jir562

38. Conradie F, Zorrilla C, Josipovic D, Botes M, Osiyemi O, Vandeloise E, et al. Safety and exposure of once-daily ritonavir-boosted atazanavir in HIV-infected pregnant women. HIV Med (2011) 12(9):570-9. doi:10.1111/j.1468-1293. 2011.00927.x

39. Mirochnick M, Best BM, Stek AM, Capparelli EV, Hu C, Burchett SK, et al. Atazanavir pharmacokinetics with and without tenofovir during pregnancy. J Acquir Immune Defic Syndr (2011) 56(5):412-9. doi:10.1097/QAI. 0b013e31820fd093

40. Lambert JS, Else LJ, Jackson V, Breiden J, Gibbons S, Dickinson L, et al. Therapeutic drug monitoring of lopinavir/ritonavir in pregnancy. HIV Med (2011) 12(3):166-73. doi:10.1111/j.1468-1293.2010.00865.x

41. Cressey TR, Jourdain G, Rawangban B, Varadisai S, Kongpanichkul R, Sabsanong $\mathrm{P}$, et al. Pharmacokinetics and virologic response of zidovudine/lopinavir/ritonavir initiated during the third trimester of pregnancy. AIDS (2010) 24(14):2193-200. doi:10.1097/QAD.0b013e32833ce57d

42. van der Lugt J, Colbers A, Molto J, Hawkins D, van der Ende M, Vogel M, et al. The pharmacokinetics, safety and efficacy of boosted saquinavir tablets in HIV type-1-infected pregnant women. Antivir Ther (2009) 14(3):443-50.

43. Bennetto-Hood C, Bryson YJ, Stek A, King JR, Mirochnick M, Acosta EP. Zidovudine, lamivudine, and nelfinavir concentrations in amniotic fluid and maternal serum. HIV Clin Trials (2009) 10(1):41-7. doi:10.1310/hct1001-041

44. Mirochnick M, Best BM, Stek AM, Capparelli E, Hu C, Burchett SK, et al. Lopinavir exposure with an increased dose during pregnancy. J Acquir Immune Defic Syndr (2008) 49(5):485-91. doi:10.1097/QAI.0b013e318186edd0 
45. Read JS, Best BM, Stek AM, Hu C, Capparelli EV, Holland DT, et al. Pharmacokinetics of new $625 \mathrm{mg}$ nelfinavir formulation during pregnancy and postpartum. HIV Med (2008) 9(10):875-82. doi:10.1111/j.1468-1293.2008. 00640.x

46. Capparelli EV, Aweeka F, Hitti J, Stek A, Hu C, Burchett SK, et al. Chronic administration of nevirapine during pregnancy: impact of pregnancy on pharmacokinetics. HIV Med (2008) 9(4):214-20. doi:10.1111/j.1468-1293.2008. 00553.x

47. Fischer JH, Sarto GE, Habibi M, Kilpatrick SJ, Tuomala RE, Shier JM, et al. Influence of body weight, ethnicity, oral contraceptives, and pregnancy on the pharmacokinetics of azithromycin in women of childbearing age. Antimicrob Agents Chemother (2012) 56(2):715-24. doi:10.1128/AAC.00717-11

48. Wang X, Nanovskaya TN, Zhan Y, Abdel-Rahman SM, Jasek M, Hankins GD, et al. Pharmacokinetics of metronidazole in pregnant patients with bacterial vaginosis. J Matern Fetal Neonatal Med (2011) 24(3):444-8. doi:10.3109/ 14767058.2010.497573

49. Beigi RH, Han K, Venkataramanan R, Hankins GD, Clark S, Hebert MF, et al. Pharmacokinetics of oseltamivir among pregnant and nonpregnant women. Am J Obstet Gynecol (2011) 204(6 Suppl 1):S84-8. doi:10.1016/j.ajog. 2011.03 .002

50. Rijken MJ, McGready R, Jullien V, Tarning J, Lindegardh N, Phyo AP, et al. Pharmacokinetics of amodiaquine and desethylamodiaquine in pregnant and postpartum women with Plasmodium vivax malaria. Antimicrob Agents Chemother (2011) 55(9):4338-42. doi:10.1128/AAC.00154-11

51. Morris CA, Onyamboko MA, Capparelli E, Koch MA, Atibu J, Lokomba V, et al. Population pharmacokinetics of artesunate and dihydroartemisinin in pregnant and non-pregnant women with malaria. Malar J (2011) 10:114. doi:10.1186/1475-2875-10-114

52. Karunajeewa HA, Salman S, Mueller I, Baiwog F, Gomorrai S, Law I, et al. Pharmacokinetics of chloroquine and monodesethylchloroquine in pregnancy. Antimicrob Agents Chemother (2010) 54(3):1186-92. doi:10.1128/AAC. 01269-09

53. Nyunt MM, Adam I, Kayentao K, van Dijk J, Thuma P, Mauff K, et al. Pharmacokinetics of sulfadoxine and pyrimethamine in intermittent preventive treatment of malaria in pregnancy. Clin Pharmacol Ther (2010) 87(2):226-34. doi:10.1038/clpt.2009.177

54. Tarning J, McGready R, Lindegardh N, Ashley EA, Pimanpanarak M, Kamanikom B, et al. Population pharmacokinetics of lumefantrine in pregnant women treated with artemether-lumefantrine for uncomplicated Plasmodium falciparum malaria. Antimicrob Agents Chemother (2009) 53(9):3837-46. doi:10.1128/AAC.00195-09

55. Karunajeewa HA, Salman S, Mueller I, Baiwog F, Gomorrai S, Law I, et al. Pharmacokinetic properties of sulfadoxine-pyrimethamine in pregnant women. Antimicrob Agents Chemother (2009) 53(10):4368-76. doi:10.1128/ AAC.00335-09

56. McGready R, Tan SO, Ashley EA, Pimanpanarak M, Viladpai-Nguen J, Phaiphun $\mathrm{L}$, et al. A randomised controlled trial of artemether-lumefantrine versus artesunate for uncomplicated Plasmodium falciparum treatment in pregnancy. PLoS Med (2008) 5(12):e253. doi:10.1371/journal.pmed.0050253

57. Muller AE, DeJongh J, Oostvogel PM, Voskuyl RA, Dorr PJ, Danhof M, et al. Amoxicillin pharmacokinetics in pregnant women with preterm premature rupture of the membranes. Am J Obstet Gynecol (2008) 198(1): 108.e1-6. doi:10.1016/j.ajog.2007.05.018

58. Roth DE, Al Mahmud A, Raqib R, Akhtar E, Black RE, Baqui AH. Pharmacokinetics of high-dose weekly oral vitamin D3 supplementation during the third trimester of pregnancy in Dhaka, Bangladesh. Nutrients (2013) 5(3):788-810. doi:10.3390/nu5030788

59. Bokhari F, Derbyshire EJ, Li W, Brennan CS. Can an iron-rich staple food help women to achieve dietary targets in pregnancy? Int J Food Sci Nutr (2012) 63(2):199-207. doi:10.3109/09637486.2011.618119

60. Hartman-Craven B, Christofides A, O’Connor DL, Zlotkin S. Relative bioavailability of iron and folic acid from a new powdered supplement compared to a traditional tablet in pregnant women. BMC Pregnancy Childbirth (2009) 9:33. doi:10.1186/1471-2393-9-33

61. Matok I, Clark S, Caritis S, Miodovnik M, Umans J, Hankins G, et al. Comparing the pharmacokinetics of doxylamine/pyridoxine delayed-release combination in nonpregnant women of reproductive age and women in the first trimester of pregnancy. J Clin Pharmacol (2013) 53(3):334-8. doi:10.1177/ 0091270012445207
62. de Oliveira Baraldi C, Moises EC, de Jesus Ponte Carvalho TM, de Jesus Antunes $\mathrm{N}$, Lanchote VL, Duarte G, et al. Effect of type 2 diabetes mellitus on the pharmacokinetics of metformin in obese pregnant women. Clin Pharmacokinet (2012) 51(11):743-9. doi:10.1007/s40262-012-0008-7

63. Zheng S, Easterling TR, Umans JG, Miodovnik M, Calamia JC, Thummel $\mathrm{KE}$, et al. Pharmacokinetics of tacrolimus during pregnancy. Ther Drug Monit (2012) 34(6):660-70. doi:10.1097/FTD.0b013e3182708edf

64. Caritis SN, Sharma S, Venkataramanan R, Hankins GD, Miodovnik M, Hebert MF, et al. Pharmacology and placental transport of 17-hydroxyprogesterone caproate in singleton gestation. Am J Obstet Gynecol (2012) 207(5): 398.e1-8. doi:10.1016/j.ajog.2012.08.015

65. Mir O, Berrada N, Domont J, Cioffi A, Boulet B, Terrier P, et al. Doxorubicin and ifosfamide for high-grade sarcoma during pregnancy. Cancer Chemother Pharmacol (2012) 69(2):357-67. doi:10.1007/s00280-011-1707-8

66. Concheiro M, Jones HE, Johnson RE, Choo R, Huestis MA. Preliminary buprenorphine sublingual tablet pharmacokinetic data in plasma, oral fluid, and sweat during treatment of opioid-dependent pregnant women. Ther Drug Monit (2011) 33(5):619-26. doi:10.1097/FTD.0b013e318228bb2a

67. de Castro A, Jones HE, Johnson RE, Gray TR, Shakleya DM, Huestis MA. Maternal methadone dose, placental methadone concentrations, and neonatal outcomes. Clin Chem (2011) 57(3):449-58. doi:10.1373/clinchem.2010.154864

68. de Castro A, Jones HE, Johnson RE, Gray TR, Shakleya DM, Huestis MA. Methadone, cocaine, opiates, and metabolite disposition in umbilical cord and correlations to maternal methadone dose and neonatal outcomes. Ther Drug Monit (2011) 33(4):443-52. doi:10.1097/FTD.0b013e31822724f0

69. Ensom MH, Stephenson MD. A two-center study on the pharmacokinetics of intravenous immunoglobulin before and during pregnancy in healthy women with poor obstetrical histories. Hum Reprod (2011) 26(9):2283-8. doi:10.1093/humrep/der227

70. Carvalho TM, Cavalli Rde C, Cunha SP, de Baraldi CO, Marques MP, Antunes NJ, et al. Influence of gestational diabetes mellitus on the stereoselective kinetic disposition and metabolism of labetalol in hypertensive patients. Eur J Clin Pharmacol (2011) 67(1):55-61. doi:10.1007/s00228-010-0896-0

71. Sit D, Perel JM, Luther JF, Wisniewski SR, Helsel JC, Wisner KL. Disposition of chiral and racemic fluoxetine and norfluoxetine across childbearing. J Clin Psychopharmacol (2010) 30(4):381-6. doi:10.1097/JCP.0b013e3181e7be23

72. Eyal S, Easterling TR, Carr D, Umans JG, Miodovnik M, Hankins GD, et al. Pharmacokinetics of metformin during pregnancy. Drug Metab Dispos (2010) 38(5):833-40. doi:10.1124/dmd.109.031245

73. Thame MM, Fletcher HM, Baker TM, Jahoor F. Comparing the glucose kinetics of adolescent girls and adult women during pregnancy. Am J Clin Nutr (2010) 91(3):604-9. doi:10.3945/ajen.2009.28635

74. Pandian RU. Dydrogesterone in threatened miscarriage: a Malaysian experience. Maturitas (2009) 65(Suppl 1):S47-50. doi:10.1016/j.maturitas. 2009.11.016

75. Nulman I, Koren G. Pharmacokinetic comparison of a delayed-release combination of doxylamine succinate and pyridoxine hydrochloride (diclectin) and oral solutions of these drugs in healthy women of childbearing age. Can J Clin Pharmacol (2009) 16(3):e400-6.

76. Cunnington M, Ephross S, Churchill P. The safety of sumatriptan and naratriptan in pregnancy: what have we learned? Headache (2009) 49(10):1414-22. doi:10.1111/j.1526-4610.2009.01529.x

77. Rampono J, Simmer K, Ilett KF, Hackett LP, Doherty DA, Elliot R, et al. Placental transfer of SSRI and SNRI antidepressants and effects on the neonate. Pharmacopsychiatry (2009) 42(3):95-100. doi:10.1055/s-0028-1103296

78. Hebert MF, Ma X, Naraharisetti SB, Krudys KM, Umans JG, Hankins GD, et al. Are we optimizing gestational diabetes treatment with glyburide? The pharmacologic basis for better clinical practice. Clin Pharmacol Ther (2009) 85(6):607-14. doi:10.1038/clpt.2009.5

79. Fotopoulou C, Kretz R, Bauer S, Schefold JC, Schmitz B, Dudenhausen JW, et al. Prospectively assessed changes in lamotrigine-concentration in women with epilepsy during pregnancy, lactation and the neonatal period. Epilepsy Res (2009) 85(1):60-4. doi:10.1016/j.eplepsyres.2009.02.011

80. Buchanan ML, Easterling TR, Carr DB, Shen DD, Risler LJ, Nelson WL, et al. Clonidine pharmacokinetics in pregnancy. Drug Metab Dispos (2009) 37(4):702-5. doi:10.1124/dmd.108.024984

81. Freeman MP, Nolan PE Jr, Davis MF, Anthony M, Fried K, Fankhauser M, et al. Pharmacokinetics of sertraline across pregnancy and postpartum. J Clin Psychopharmacol (2008) 28(6):646-53. doi:10.1097/JCP.0b013e31818d2048 
82. Lebaudy C, Hulot JS, Amoura Z, Costedoat-Chalumeau N, Serreau R, Ankri A, et al. Changes in enoxaparin pharmacokinetics during pregnancy and implications for antithrombotic therapeutic strategy. Clin Pharmacol Ther (2008) 84(3):370-7. doi:10.1038/clpt.2008.73

83. Jain S, Zharikova OL, Ravindran S, Nanovskya TN, Mattison DR, Hankins GD, et al. Glyburide metabolism by placentas of healthy and gestational diabetics. Am J Perinatol (2008) 25(3):169-74. doi:10.1055/s-2008- 1061503

84. Haapsamo M, Martikainen H, Rasanen J. Low-dose aspirin reduces uteroplacental vascular impedance in early and mid gestation in IVF and ICSI patients: a randomized, placebo-controlled double-blind study. Ultrasound Obstet Gynecol (2008) 32(5):687-93. doi:10.1002/uog.6215

85. Hebert MF, Easterling TR, Kirby B, Carr DB, Buchanan ML, Rutherford T, et al. Effects of pregnancy on CYP3A and P-glycoprotein activities as measured by disposition of midazolam and digoxin: a University of Washington specialized center of research study. Clin Pharmacol Ther (2008) 84(2):248-53. doi:10.1038/clpt.2008.1

86. Allegaert K, van Calsteren K, Hendrickx S, Kelchtermans J, Smits A, Kulo A, et al. Paracetamol and ketorolac pharmacokinetics and metabolism at delivery and during postpartum. Acta Anaesthesiol Belg (2012) 63(3):121-5.

87. Kulo A, Hendrickx S, de Hoon J, Mulabegovic N, van Calsteren K, Verbesselt $\mathrm{R}$, et al. The impact of pregnancy on urinary ketorolac metabolites after single intravenous bolus. Eur J Drug Metab Pharmacokinet (2013) 38(1):1-4. doi:10.1007/s13318-012-0108-7

88. Tran KM, Maxwell LG, Cohen DE, Adamson PC, Moll V, Kurth CD, et al Quantification of serum fentanyl concentrations from umbilical cord blood during ex utero intrapartum therapy. Anesth Analg (2012) 114(6):1265-7. doi:10.1213/ANE.0b013e3182378d21

89. Patterson KB, Dumond JB, Prince HA, Jenkins AJ, Scarsi KK, Wang R, et al. Protein binding of lopinavir and ritonavir during 4 phases of pregnancy: implications for treatment guidelines. J Acquir Immune Defic Syndr (2013) 63(1):51-8. doi:10.1097/QAI.0b013e31827fd47e

90. Benaboud S, Hirt D, Launay O, Pannier E, Firtion G, Rey E, et al. Pregnancyrelated effects on tenofovir pharmacokinetics: a population study with 186 women. Antimicrob Agents Chemother (2012) 56(2):857-62. doi:10.1128/AAC. 05244- 11

91. Benaboud S, Treluyer JM, Urien S, Blanche S, Bouazza N, Chappuy H, et al. Pregnancy-related effects on lamivudine pharmacokinetics in a population study with 228 women. Antimicrob Agents Chemother (2012) 56(2):776-82. doi:10.1128/AAC.00370-11

92. Calza L, Manfredi R, Trapani F, Salvadori C, Colangeli V, Borderi M, et al. Lopinavir/ritonavir trough concentrations with the tablet formulation in HIV1-infected women during the third trimester of pregnancy. Scand J Infect Dis (2012) 44(5):381-7. doi:10.3109/00365548.2011.642306

93. Hoglund RM, Adam I, Hanpithakpong W, Ashton M, Lindegardh N, Day NP, et al. A population pharmacokinetic model of piperaquine in pregnant and non-pregnant women with uncomplicated Plasmodium falciparum malaria in Sudan. Malar J (2012) 11:398. doi:10.1186/1475-2875-11-398

94. Tarning J, Chotsiri P, Jullien V, Rijken MJ, Bergstrand M, Cammas M, et al. Population pharmacokinetic and pharmacodynamic modeling of amodiaquine and desethylamodiaquine in women with Plasmodium vivax malaria during and after pregnancy. Antimicrob Agents Chemother (2012) 56(11):5764-73. doi:10.1128/AAC.01242-12

95. Tarning J, Kloprogge F, Piola P, Dhorda M, Muwanga S, Turyakira E, et al. Population pharmacokinetics of artemether and dihydroartemisinin in pregnant women with uncomplicated Plasmodium falciparum malaria in Uganda. Malar $J$ (2012) 11:293. doi:10.1186/1475-2875-11-293

96. Adam I, Tarning J, Lindegardh N, Mahgoub H, McGready R, Nosten F. Pharmacokinetics of piperaquine in pregnant women in Sudan with uncomplicated Plasmodium falciparum malaria. Am J Trop Med Hyg (2012) 87(1):35-40. doi:10.4269/ajtmh.2012.11-0410

97. Tarning J, Rijken MJ, McGready R, Phyo AP, Hanpithakpong W, Day NP, et al. Population pharmacokinetics of dihydroartemisinin and piperaquine in pregnant and nonpregnant women with uncomplicated malaria. Antimicrob Agents Chemother (2012) 56(4):1997-2007. doi:10.1128/AAC.05756-11

98. McGready R, Phyo AP, Rijken MJ, Tarning J, Lindegardh N, Hanpithakpon $\mathrm{W}$, et al. Artesunate/dihydroartemisinin pharmacokinetics in acute falciparum malaria in pregnancy: absorption, bioavailability, disposition and disease effects. Br J Clin Pharmacol (2012) 73(3):467-77. doi:10.1111/j.1365-2125. 2011.04103.x

99. Roth DE, Al Mahmud A, Raqib R, Black RE, Baqui AH. Pharmacokinetics of a single oral dose of vitamin D3 (70,000 IU) in pregnant and non-pregnant women. Nutr J (2012) 11:114. doi:10.1186/1475-2891-11-114

100. Tiblad E, Wikman A, Rane A, Jansson Y, Westgren M. Pharmacokinetics of 250 mug anti-D IgG in the third trimester of pregnancy: an observational study. Acta Obstet Gynecol Scand (2012) 91(5):587-92. doi:10.1111/j.1600-0412.2012. 01377.x

101. Zelinkova Z, van der Ent C, Bruin KF, van Baalen O, Vermeulen HG, Smalbraak $\mathrm{HJ}$, et al. Effects of discontinuing anti-tumor necrosis factor therapy during pregnancy on the course of inflammatory bowel disease and neonatal exposure. Clin Gastroenterol Hepatol (2013) 11(3):318-21. doi:10.1016/j.cgh.2012.10.024

102. Ke AB, Nallani SC, Zhao P, Rostami-Hodjegan A, Isoherranen N, Unadkat JD. A physiologically based pharmacokinetic model to predict disposition of CYP2D6 and CYP1A2 metabolized drugs in pregnant women. Drug Metab Dispos (2013) 41(4):801-13. doi:10.1124/dmd.112.050161

103. Gaohua L, Abduljalil K, Jamei M, Johnson TN, Rostami-Hodjegan A. A pregnancy physiologically based pharmacokinetic (p-PBPK) model for disposition of drugs metabolized by CYP1A2, CYP2D6 and CYP3A4. Br J Clin Pharmacol (2012) 74(5):873-85. doi:10.1111/j.1365-2125.2012.04363.x

104. Chen L, Magliano DJ, Zimmet PZ. The worldwide epidemiology of type 2 diabetes mellitus - present and future perspectives. Nat Rev Endocrinol (2012) 8(4):228-36. doi:10.1038/nrendo.2011.183

105. Bell R, Bailey K, Cresswell T, Hawthorne G, Critchley J, Lewis-Barned N, et al. Trends in prevalence and outcomes of pregnancy in women with pre-existing type I and type II diabetes. BJOG (2008) 115(4):445-52. doi:10.1111/j.14710528.2007.01644.x

106. Secher AL, Mathiesen ER, Andersen HU, Peter D, Lene R. Severe hypoglycemia in pregnant women with type 2 diabetes-A relevant clinical problem. Diabetes Res Clin Pract (2013) 102(2):e17-8. doi:10.1016/j.diabres.2013.09.011

107. Thorpe PG, Gilboa SM, Hernandez-Diaz S, Lind J, Cragan JD, Briggs G, et al. Medications in the first trimester of pregnancy: most common exposures and critical gaps in understanding fetal risk. Pharmacoepidemiol Drug Saf (2013) 22(9):1013-8. doi:10.1002/pds.3495

108. CDC. QuickStats: prevalence of current depression among persons aged $\geq$ 12 years, by age group and sex - United States, National Health and Nutrition Examination survey, 2007-2010. MMWR Morb Mortal Wkly Rep (2012) 60(51 \& 52): 1747 .

109. Rodriguez WJ, Roberts R, Murphy D. Current regulatory policies regarding pediatric indications and exclusivity. J Pediatr Gastroenterol Nutr (2003) 37(Suppl 1):S40-5. doi:10.1097/00005176-200311001-00009

110. Ward RM, Kauffman R. Future of pediatric therapeutics: reauthorization of BPCA and PREA. Clin Pharmacol Ther (2007) 81(4):477-9. doi:10.1038/sj. clpt.6100109

111. Food, Drug Administration HHS. Additional safeguards for children in clinical investigations of food and drug administration-regulated products. Fed Regist (2013) 78(38):12937-51.

Conflict of Interest Statement: The authors declare that the research was conducted in the absence of any commercial or financial relationships that could be construed as a potential conflict of interest.

Received: 13 November 2013; accepted: 26 January 2014; published online: 11 February 2014.

Citation: McCormack SA and Best BM (2014) Obstetric pharmacokinetic dosing studies are urgently needed. Front. Pediatr. 2:9. doi: 10.3389/fped.2014.00009

This article was submitted to Obstetric and Pediatric Pharmacology, a section of the journal Frontiers in Pediatrics.

Copyright (C) 2014 McCormack and Best. This is an open-access article distributed under the terms of the Creative Commons Attribution License (CC BY). The use, distribution or reproduction in other forums is permitted, provided the original author(s) or licensor are credited and that the original publication in this journal is cited, in accordance with accepted academic practice. No use, distribution or reproduction is permitted which does not comply with these terms. 